\title{
The celiac axis compression syndrome (CACS): critical review in the laparoscopic era
}

\author{
J. A.-Cienfuegos ${ }^{1}$, F. Rotellar ${ }^{1}$, V. Valentí ${ }^{1}$, J. Arredondo ${ }^{1}$, N. Pedano ${ }^{1}$, A. Bueno ${ }^{1}$ and I. Vivas ${ }^{2}$ \\ Departments of ${ }^{1}$ General and Digestive Surgery and ${ }^{2}$ Radiology. Clínica Universidad de Navarra. Pamplona, Spain
}

\begin{abstract}
The celiac axis compression syndrome (CACS) due to median arcuate ligament (MAL) was first described by Harjola in 1963; originating postpandrial abdominal pain, weight loss, epigastric bruit and celiac axis stenosis $>75 \%$ in angiographic studies. This clinical condition has been the origin of controversies about its pathogenesis, diagnosis and its long term clinical results.

Advances in diagnostic imaging as 64 multidetector-row CT (MDCT), 3-D reconstruction, magnetic resonance (MR) and color duplex ultrasonography, provide better understanding of the syndrome and allow to identify the best candidates for surgical division of MAL fibers.

Since the introduction of laparoscopic approach, and also endovascular procedures, in 2000, a new perspective has established in this challenging syndrome. With the occasion of our own experience, a critical review of the syndrome is presented.
\end{abstract}

Key words: Celiac axis compression. Median arcuate ligament. Laparoscopic treatment.

A.-Cienfuegos J, Rotellar F, Valentí V, Arredondo J, Pedano $N$, Bueno A, Vivas I. The celiac axis compression syndrome (CACS): critical review in the laparoscopic era. Rev Esp Enferm Dig 2010; 102: 193-201.

\section{INTRODUCTION}

The celiac axis compression syndrome (CACS), also known as median arcuate ligament (MAL), was first de-

Received: 06-05-09.

Accepted: 14-05-09.

Correspondence: Javier A.-Cienfuegos. Department of General Surgery. Clínica Universidad de Navarra. Avda. Pío XII, 36. 31008 Pamplona. e-mail: fjacien@unav.es scribed by Harjola in 1963. In 1965 Durban reported the first cases serie with surgery $(1,2)$.

The syndrome is clinically characterized by the triade: postpandrial abdominal pain, presence of an epigastric bruit which increases in expiration and the assessment of extrinsic compression $(>50 \%)$ of the celiac axis by the arcuate ligament by vascular imaging (angiography, CTangiography, etc.).

Since the first description, the syndrome has been submitted to several controversies based on the variabilities in the results and also different physiopathological interpretations. Some authors have considered the CACS as the most frequent cause of chronic mesenteric ischemia, meanwhile its existence has been challenged by other authors (3-8). The introduction of CT-angiography with three-dimensional reconstruction, duplex abdominal ultrasound (US) and laparoscopic surgery has promoted a renewed interest in the syndrome. We present a critical review of the pathogenic mechanisms, the therapeutic options and results.

\section{ANATOMIC BASES}

The arcuate ligament is formed by tendinous fibers between the two diaphragmatic cruras, which form the ventral arch of the aortic hiatus of which four variants have been reported. An abnormal fibrous thickening of MAL obstructing from 70 to $100 \%$ of the celiac trunk lumen has been previously reported in necropsy findings and surgical descriptions as well (9-12).

Another cause of the syndrome has been related with the celiac trunk $(\mathrm{CT})$ origin in the aorta. The CT origines between the 11 thoracic and first lumbar vertebra. The mentioned origin can be located craneally within the thorax, causing a compression by the MAL's fibres $(1,9,12)$. A craneally origin of the CT has been described in patients with astenic habitus. Some of the patients describe 
a pain relief with the knee-chest position, due to the relaxing of the vessels impingement by the MAL.

Charette, Balaban and other authors $(13,14)$, related the symptons with a thickening of the celiac plexus sustaining an extrinsic compression of the CT with flow impairment (15-19).

The syndrome is more frequent in young females with a thin body habitus, who many of them have previous history of weight loss as consequence of the intense postpandrial pain. As matter of fact, one of the characteristics of good response to surgical release was the mentioned above according to a seminal paper of Reilly, published in 1985, who reported the long-term follow-up (median 9 years, range 1-18) of 51 patients surgically treated (20).

A simultaneous stenosis of the celiac trunk with superior mesenteric artery and renal arteries compression originating chronic intestinal ischemia and renovascular hypertension have described (21-23).

\section{PHISIOPATHOLOGY}

Several hipothesis have been proposed regarding the origin of the syndrome, although is a topic of academic debate. The most common theory relates the symptons with the visceral ischemia originated by the extrinsic compression of the CT. In support of this there are the radiologic findings (CT-angiography, MR-angiography), the surgical descriptions and the symptons release (close to $80 \%$ ) after surgical division of the MAL and release of the CT $(4-6,18,23-25)$.

By contrast, another facts question this mechanism. The most mentioned is the experimental and clinical evidence that the complete occlusion of two of three main major abdominal arteries are required to provoque abdominal angina, as have been shown in animals or in oncologic and thoracoabdominal aneurism cases $(7,11,26)$.

In 1969 , Bron et al. reported $12.5 \%$ of asymptomatic patients with "radiologic findings" of CT compression. In 1972 Colapinto found signs of compression and stenosis on the $31 \%$ of asymptomatic patients $(27,28)$. These data and the symptoms recurrence following the surgical division of the MAL would support the caution in attributing the patients' symptoms to the arterial occlusion and the existence of the syndrome $(4,5,26)$.

The second pathogenic theory is known as "steal phenomenon" by which blood from superior mesenteric artery territory is diverted through collateral vessels concurrent with a high demand of oxygen by the gut. Kalapatapu has recently reproduced the symptoms inducing a selective splachnic vasodilatation in the superior mesenteric artery (31). In the experience of this author, the induction of symptoms is a clear sign for selecting surgical candidates, obtaining a $75 \%$ of success with MAL release.

In favour of this theory would be the reported consequences in young athletes after intense exercise in liver transplantation and following pancreatoduodenectomies in patients who had an unnoticed celiac trunk compression $(29,30,32-35)$.

\section{CLINICAL FEATURES AND DIAGNOSIS}

The intense postpandrial epigastric pain (mean duration 20-30 minutes), nausea and vomiting are the most common symptons. The postpandrial pain induces a "food fear" and avoid eating, being cause of weight loss $(5-10 \mathrm{~kg})$. The pain may be relieved in the knee-chest position, and is more frequent in young females (3/1) about 40-50 years; although it has been reported in children and adults. The mean duration of symptoms range between three months and more than 10 years $(5,7,11,20,23,26,27$, 36).

Because of the difficulty in diagnosis of the syndrome, many patients have been previously diagnosed of functional disorders and had undergone an extensive gastrointestinal evaluation including endoscopy, motility studies, abdominal CT or sugical intervention as exploratory laparoscopy/laparotomy, without establishing a diagnosis. In some series, $10-15 \%$ of the patients had psiquiatric antecedents $(5,7,11,36)$.

On physical examination, patients usually have a thin and leptosomatic habitus and an epigastric bruit -which increases in deep expiration- is present in $83 \%$ $(20,24,37)$; although abdominal bruits occur in approximately $30 \%$ of healthy adults $(18,38)$.

\section{Imaging studies}

The radiologic confirmation of $\mathrm{CT}$ compression and severe stenosis or occlusion is mandatory for the diagnosis. The gold standard of CTC syndrome was aortic-arteriography with lateral aortogram until the introduction of CT-angiography, 3D reconstruction and magnetic resonance (MR)-angiography.

In the lateral projections of aortography and selective mesenteric studies, an image of "hook" -characteristic of the MAL effect upon celiac axis- is assessed (Fig. 1). Postestenotic dilatation, collateral circulation and pancreaticoduodenal artery aneurisms have been reported $(7,11,20,28)$. The patency of superior mesenteric artery and renal arteries must be evaluated. Duplex ultrasound have shown to be useful in assesing changes in CT orientation and increase in the peak systolic velocity $(>1,8$ $\mathrm{m} / \mathrm{sec}$ ) in inspiration $v s$. expiration (39).

Currently the thin-section multidetector CT scanners along with 3D software in sagital plane is optimal for assesing the proximal portion of the celiac trunk, ruling out other causes of celiac artery occlusion or narrowing as atherosclerotic disease (40-42) (Fig. 2). 


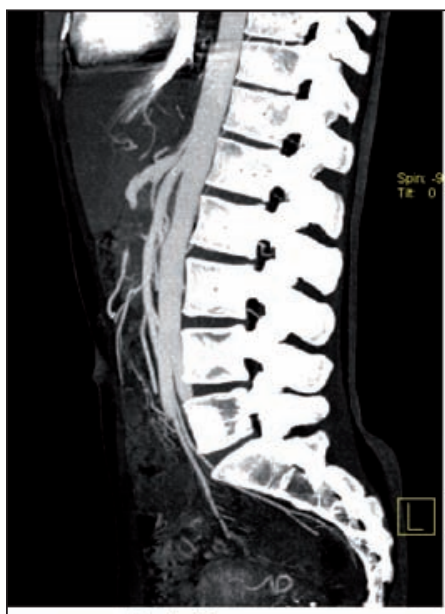

Inspiration

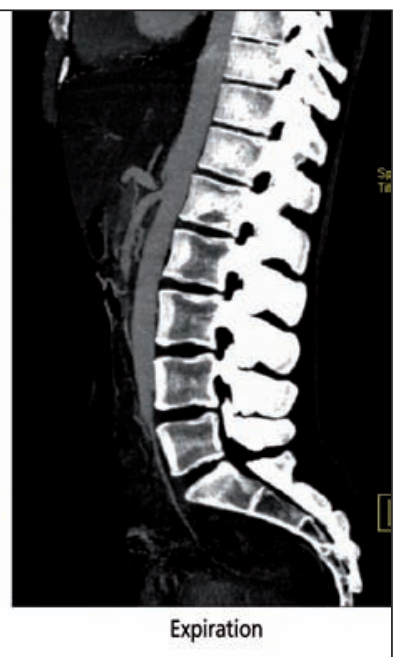

Fig. 1. Sagital contrast entrance volume-rendered technique showing hooked appearance and CT stenosis in a patient with postpandrial pain.

Estenosis tronco celiaco. Imagen sagital. Imagen 3D de una paciente con dolor agudo postpandrial y que muestra una angulación y estenosis del tronco celiaco.

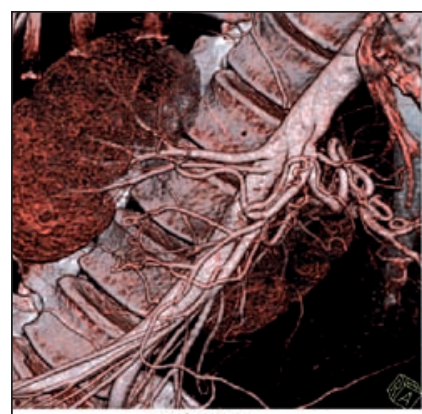

Inspiration

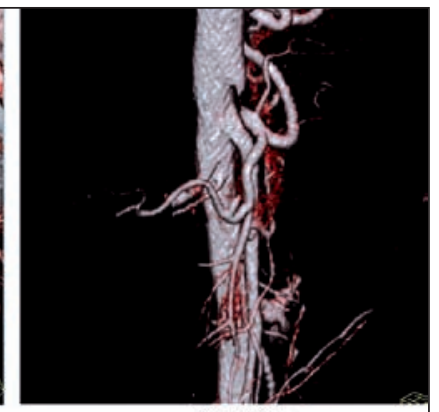

Expiration
Fig. 2. Sagital 3-D volume-rendered image showing the CT stenosis in expiration.

Estenosis tronco celiaco. Imagen sagital y reconstrucción 3D con contraste mostrando la estenosis marcada en espiración.

Some authors have developed more specific studies in order to asses the CT occlusion and stablish a more precise surgical indication. Mensik et al. studied 320 patients with symptons of chronic intestinal ischemia, with selective angiography and gastric tonometry, yelded the CT syndrome in 43 patients (13.4\%), indicating the surgical treatment exclusively in those who presented signs of gastric ischemia (gradient intraluminal gastric and arterial $\mathrm{PCO}_{2}$ ), (43), obtaining a $83 \%$ of symptoms relieve in these patients.

We have previously described how Kalapatapu y cols. reproduced the gastric ischemic signs by inducing in four patients a selective vasodilatation in the splachnic bed, with $75 \%$ of abdominal pain resolution in the surgically treated. These findings confirm the ischemic theory of the syndrome and establish an objective criteria for surgical selection (31).

\section{TREATMENT}

Several endovascular procedures as angioplasty with or without stenting have been carried out with poor results. The sustained ant tight compression of the diaphragmatic fibers led to permanent changes on the vessel wall, fragmenting the stents and making this procedure unsuccesfull (44).

The other surgical techniques are the simple surgical division of the MAL and CT release with blood flow restoration assessing by Doppler-US and other complex procedures including vascular reconstruction with patch angioplasty of the celiac artery, aortoceliac bypass with saphenous vein or Dacron graft and reimplantation of the celiac trunk in the aorta $(20,44,45-47)$.

The most common procedure is the surgical division of the constrictive fibers of the celiac plexus and release of the celiac trunk up its origin the aorta (Table I). Since the introduction of the laparoscopic approach in 2000, excelent results -with the benefits of this procedure, less hospital stay, faster recovering, less postoperative pain, etc. (48-55)have been reported. The technique is depicted in figure 3 .

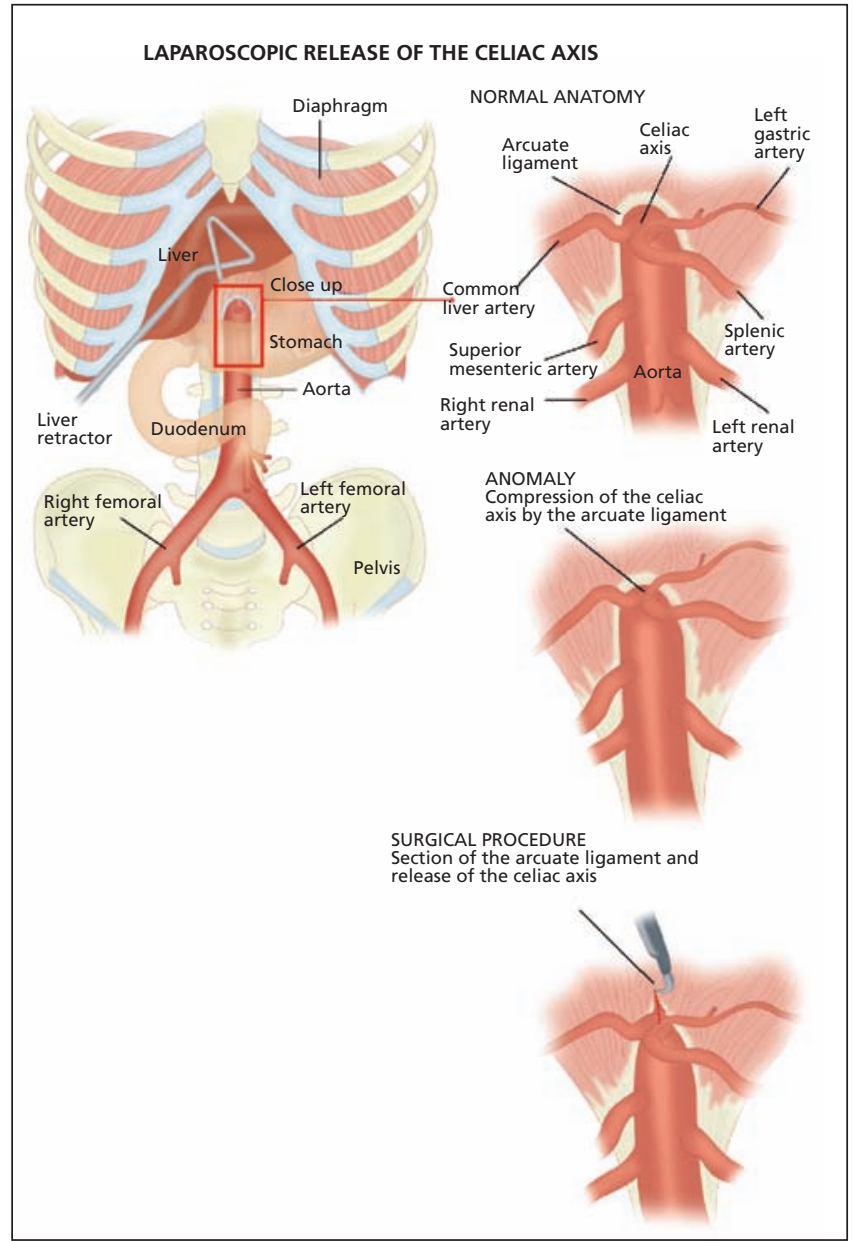

Fig. 3. A diaphragmatic representation of laparoscopic MAL division and $\mathrm{CT}$ release.

Representación esquemática de la técnica laparoscópica de la sección del ligamento arcuato y liberación del tronco celiaco. 
Table I. Results obtained by the simple division of the MAL in the most numerous series

\begin{tabular}{|c|c|c|c|c|c|}
\hline Author (ref.) & Year & \# cases & Release $M A L^{*}$ & Improvement \% & Follow-up \\
\hline Dunbar (2) & 1965 & 13 & 13 & $69 \%$ & 9-15 months \\
\hline Szilagyi**(4) & 1972 & 165 & 129 & $82 \%$ & 1 month-4 years \\
\hline Evans (5) & 1974 & 47 & 47 & $83 \%$ & 6 months- 11 years \\
\hline Watson (36) & 1977 & 20 & 20 & $80 \%$ & 6 months- 4 years \\
\hline Reilly (20) & 1985 & 51 & 33 & $65 \%$ & 1 year- 18 years \\
\hline
\end{tabular}

*MAL: median arcuate ligament; **Literature review 1963-1971.

Table II. Experience with laparoscopic approach in the treatment of CTC syndrome

\begin{tabular}{|c|c|c|c|c|c|c|c|}
\hline \multirow[t]{2}{*}{ Author (ref.) } & \multirow[t]{2}{*}{ Year } & \multirow[t]{2}{*}{ \# cases } & \multicolumn{2}{|c|}{ Surgery } & \multirow[t]{2}{*}{ Hospital stay } & \multirow[t]{2}{*}{ Follow-up } & \multirow[t]{2}{*}{ Improvement } \\
\hline & & & Lenght & Blood loss & & & \\
\hline Roayaie (48) & 2002 & 1 & $135 \mathrm{~min}$ & $55 \mathrm{cc}$ & 15 hours & 3 months & Yes \\
\hline Dordoni (49) & 2002 & 1 & $125 \mathrm{~min}$ & $65 c c$ & 48 hours & 6 months & Yes \\
\hline Carbonell (50) & 2005 & 1 & & & 72 hours & 7 months & Yes \\
\hline Baldassarre (51) & 2007 & 1 & $130 \mathrm{~min}$ & - & No data & 3 months & Yes \\
\hline Jaik** (52) & 2008 & 1 & $160 \mathrm{~min}$ & $50 \mathrm{cc}$ & 48 hours & 6 months & Yes \\
\hline Jarry (53) & 2008 & 1 & $168 \mathrm{~min}$ & - & 24 hours & 1.5 months & Yes \\
\hline Duffy (55) & 2008 & 1 & $218 \mathrm{~min}$ & - & 24 hours & 10 months & Yes \\
\hline Vaziri (54) & 2009 & 3 & $\begin{array}{c}\bar{X}: 151 \min \\
\text { (range: } 114-217 \text { ) }\end{array}$ & $<50 \mathrm{cc}$ & 24 hours & 6 months & Yes \\
\hline Rotellar* & 2009 & 7 & $\begin{array}{c}\bar{X}: 111 \min \\
\text { (range: } 90-120)\end{array}$ & $<50$ cc & $\begin{array}{c}65 \text { hours } \\
\text { (range 48-96) }\end{array}$ & 6 months- 8 years & $\begin{array}{c}\text { Yes 2/3 } \\
\text { Average 1/3 }\end{array}$ \\
\hline
\end{tabular}

*Authors' results in 2009; ** Surgery using Da Vinci Surgical System (Intuitive Surgical, Sunnyvale, California).

The cases reported in these series were well selectionated: young females with intense pain and weight loss. In our experience of 7 cases underwent surgery by laparoscopic technique, similar results were obtained (Table II).

As mentioned before, the results have been variable. Perhaps the main reason of that is the short-term followup and the diversity of abdominal pain medical profiles diagnosed as CTC syndrome.

The seminal paper paper published by Reilly in 1985 describing the long-term follow-up of 51 patiens treated surgically was crucial for explaining these divergences. In this report, $80 \%$ of young patients (40-60 years) with postpandrial pain, weight loss and postestenotic dilatation in the celiac angiogram, releaved the symptoms. Similar results were published by other authors and the same prognostic factors were found in regression studies: epigastric pain related with ingesta as more relevant parameter $(20,46,56,57)$.

The accumulated experience points out the importance of a detalied anamnesis and the selective imaging techniques as Doppler-US, CT-angiography; avoiding unnecessary explorations.

The laparoscopic approach and minimally invasive techniques: MAL division, with ulterior endovascular techniques when necessary -angioplasty, Stent-, open a new "era" in the diagnosis and treatment of the syndrome described in 1963.

\section{ACKNOWLEDGEMENT}

The authors thank Lydia Munárriz for editing the manuscript.

\section{REFERENCES}

1. Harjola PT. A rare obstruction of the coeliac artery: report of a case. Ann Chir Gynaecol Fenn 1963; 52: 547-50.

2. Dunbar JD, Molnar W, Beman FF, Marable SA. Compression of the celiac trunk and abdominal angina: preliminary report of 15 cases. Am J Roentgenol 1965; 95(3): 731-44.

3. Edwards A. Coeliac axis compression syndrome. Proc R Soc Med 1969; 62: 488-90.

4. Szilagyi DE, Rian RL, Elliott JP, Smith RF. The celiac artery compression syndrome: does it exist? Surgery 1972; 72(6): 849-63.

5. Evans WE. Long-term evaluation of the celiac band syndrome. Surgery 1974; 76: 867-71.

6. Mihas A, Laws H, Jander H. Surgical treatment of the celiac axis compression syndrome. Ann J Surg 1977; 133: 688-91.

7. Brandt LJ, Boley SJ. Celiac axis compression syndrome. A critial review. Digest Dis 1978; 23: 633-40.

8. Gloviczki P, Duncan A. Treatment of celiac artery compression syn- 
drome: does it really exist? Perspect Vas Surg Endovasc Therap 2007; 19: 259-63.

9. Linder H, Kemprud E. A clinicoanatomical study of the arcuate ligament of the diaphragm. Arch Surg 1971; 103: 600-5.

10. Mulder D, Rubush J, Lawrence M, Ehrenhaft J. Celiac axis compression syndrome. Can J Surg 1971; 14: 122-6.

11. Bergquist D. Celiac artery compression syndrome. En: Geroulakos G, Cherry KJ Jr., editors. Diseases of the visceral circulation. London: Arnold; 2002. p. 119-29.

12. Loukas M, Pinyard J, Sumreen Vaid S, Kinsella C, Tariq A, Tubbs RS. Clinical anatomy of celiac artery compression syndrome: a review. Clin Anat 2007; 20: 612-7.

13. Charette EP, Iyengar SRK, Lynn RB, Paloschi GB, West RO. Abdominal pain associated with celiac artery compression. Surg Gynecol Obstet 1971; 132: 1009-14.

14. Balaban DH, Chen J, Lin Z, Tribble CG, McCallum RW. Median arcuate ligament syndrome: a possible cause of idiopathic gastroparesis. Am J Gastroenterol 1997; 92: 519-23.

15. Rob C. Surgical diseases of the celiac and mesenteric arteries. Arch Surg 1966; 93: 21-32.

16. Rob C. Stenosis and thrombosis of the celiac and mesenteric arteries. Am J Surg 1976; 114: 363-7.

17. Gutnik LM. Celiac artery compression syndrome. Am J Med 1984; 76: 334-6.

18. Watson W, Williams P, Duffy G. Epigastric bruits in patients with and without celiac axis compression. Ann Intern Med 1973; 79: 2115.

19. Feindt $\mathrm{P}$, Walter $\mathrm{P}$, Omlor G. Das kompressionssyndrom des truncus coeliacus: Ein seltenes Krankheitsbild. VASA 1992; 21: 307-9.

20. Reilly LM, Ammar AD, Stoney RJ, Ehrenfeld WK. Late results following operative repair for celiac artery compression syndrome. J Vasc Surg 1985; 2: 79-91.

21. Kopecky KK, Stine SB, Dalsing MC, Gottlieb K. Median arcuate ligament syndrome with multivessel involvement: diagnosis with spiral CT angiography. Abdom Imaging 1997; 22: 318-20.

22. Lawson JD, Ochsner JL. Median arcuate ligament syndrome with severe two-vessel involvement. Arch Surg 1984; 119: 226-7.

23. Ghosn PB, Rabbat AG, Trudel J, D'Amico P, Lecours R. Celiac compression syndrome. Can J Surg 1982; 25: 377-9.

24. Lord RS, Tracy GD. Coeliac artery compression. Br J Surg 1980; 67(8): 590-3.

25. Duncan AA. Median arcuate ligament syndrome. Current Treat Opt Cardiovasc Med 2008; 10: 112-6.

26. Plate G, Eklof B, Vang J. The celiac compression syndrome: myth or reality? Acta Chir Scand 1981; 147(3): 201-3.

27. Bron KM, Redman HC. Splanchnic artery stenosis and occlusion incidence, arteriographic and clinical manifestations. Radiology 1969; 92: 323-8.

28. Colapinto RF, McLoughlin MJ, Weisbrod GL. The routine lateral aortogram and the celiac compression syndrome. Radiology 1972; 103: 557-63

29. Desmond CP, Roberts SK. Exercise-related abdominal pain as a manifestation of the median arcuate ligament syndrome. Scand J Gastroenterol 2004; 39: 1310-3.

30. Tseng YC, Tseng CK, Chou JW, Lai HC, Hsu CH, Cheng KS, et al. A rare cause of mesenteric ischemia: celiac axis compression syndrome. Intern Med 2007; 46(15): 1187-90.

31. Kalapatapu VR, Murray BW, Palm-Cruz K, Ali AT, Moursi MM, Eidt JF. Definitive test to diagnose median arcuate ligament syndrome: injection of vasodilator during angiography. Vasc Endovasc Surg 2009; 43: 46-50.

32. Fortner J, Watson R. Median arcuate ligament obstruction of celiac axis and pancreatic cancer. Ann Surg 1981; 194: 698-700.

33. Fukuzawa K, Schwartz M, Katz E. The arcuate ligament syndrome in liver transplantation. Transplantation 1993; 56: 223-4

34. Lubrano J, Scatton O, Randome B, Molinier N, Massault PP, Legman $\mathrm{P}$, et al. Median arcuate ligament in orthotopic liver transplantation: relevance to arterial reconstruction. Transp Proc 2008; 40: $3532-5$.
35. Ducerf C, Rode A, De la Roche E, Beck F, Adham M, Berthoux N, et al. Compression du tronc celiaque par le ligament arqué du diaphragme au cours de la chirurgie de l'etage sus-mesocolique. Ann Chir 1998; 52: 495-502.

36. Watson WC, Sadikali F. Experience with 20 patients and a critical appraisal of the syndrome. Ann Intern Med 1977; 86: 278-84.

37. Bech F. Celiac artery compression syndromes. Surg Clin North Am 1997; 77: 409-24.

38. Julius S, Stewart B. Diagnostic significance of abdominal murmurs. N Engl J Med 1972; 276: 1175-8.

39. Sproat IA, Pozniak MA, Kennell TW. US case of the day: median arcuate ligament syndrome. RadioGraphics 1993; 13: 1400-2.

40. Norton KM, Talamini MA, Fishman EK. Median arcuate ligament syndrome: evaluation with CT angiography. RadioGraphics 2005; 25: $1177-82$.

41. Ilica AT, Kocaoglu M, Bilici A, Ors F, Bukte Y, Senol A, et al. Median arcuate ligament syndrome: multidetector computed tomography findings. J Comput Assist Tomogr 2007; 31(5): 728-31.

42. Manghat NE, Mitchell G, Hay CS, Wells IP. The median arcuate ligament syndrome revisited by CT angiography and the use of ECG gating - a single centre case series and literature review. Br J Radiol 2008; 81: 735-42.

43. Mensink PB, van Petersen AS, Kolkman JJ, Otte JA, Huisman AB, Geelkerken RH. Gastric exercise tonometry: the key investigation in patients with suspected celiac artery compression syndrome. J Vasc Surg 2006; 44(2): 277-81.

44. Delis KT, Gloviczki P, Altuwaijri M, McKusick MA. Median arcuate ligament syndrome: Open celiac artery reconstruction and ligament division after endovascular failure. J Vasc Surg 2007; 46: 799802 .

45. Geelkerken RH, van Bockel JH, de Roos WK, Hermans, J. Coeliac artery compression syndrome: the effect of decompression. Br J Surg 1990; 77: 807-9.

46. Takach TJ, Livesay JJ, Reul GJ, Cooley DA. Celiac compression syndrome: tailored therapy based on intraoperative findings. J Am Coll Surg 1996; 183: 606-10.

47. Kokotsakis JN, Lambidis CD, Lioulias AG, Skouteli ET, Bastounis EA, Livesay JJ. Celiac artery compression syndrome. Cardiovasc Surg 2000; 8(3): 219-22.

48. Roayaie S, Jossart G, Gitlitz D, Lamparello P, Hollier L, Gagner M. Laparoscopic release of celiac artery compression syndrome facilitated by laparoscopic ultrasound scanning to confirm restoration of flow. J Vasc Surg 2000; 32: 814-7.

49. Dordoni L, Tshomba Y, Giacomelli M, Jannello AM, Chiesa R. Celiac artery compression syndrome: successful laparoscopic treatment: a case report. Vasc Endosvasc Surg 2002; 36: 317-21.

50. Carbonell AM, Kercher KW, Heniford BT, Matthews BD. Laparoscopic management of median arcuate ligament syndrome. Surg Endosc 2005; 19: 729 .

51. Baldassarre E, Torino G, Siani A, Barone M, Valenti G. The laparoscopic approach in the median arcuate ligament syndrome: report of a case. Swiss Med Wkly 2007; 137(23-24): 353-4.

52. Jaik NP, Stawicki SP, Weger NS, Luzkaszczyk JJ. Celiac artery compression syndrome: successful utilization of robotic-assisted laparoscopic approach. J Gastrointestin Liver Dis 2007; 16: 93-6.

53. Jarry J, Berard X, Ducasse E, Biscay D, Pailler A, Sassoust G, et al. Traitement du syndrome du ligament arqué médian par voie coelioscopique. J Malad Vas 2008; 33: 30-4.

54. Vaziri K, Hungness ES, Pearson EG, Soper NJ. Laparoscopic treatment of celiac artery compression syndrome: case series and review of current treatment modalities. J Gastrointest Surg 2009; 13: 293-8.

55. Duffy AJ, Parrait L, Eisenberg D, Bell RL, Roberts KE, Sumpio B. Management of median arcuate ligament syndrome: a new paradigm. DOI: 10.1016/j.avsg.2008.11.005

56. Williams S, Gillespe P, Little J. Celiac axis compression syndrome: factors predicting a favourable outcome. Surgery 1985; 98: 879-87.

57. Macarrone-Palmieri R, Beya A, Boumghar M, Chapuis G, Saegesser F. Compression du tronc coeliaque par ligament arqué au diaphragme. Helv Chir Acta 1979; 46: 239-44. 